\title{
The ability of NT-proBNP to detect chronic heart failure and predict all-cause mortality is higher in elderly Chinese coronary artery disease patients with chronic kidney disease
}

\author{
This article was published in the following Dove Press journal: \\ Clinical Interventions in Aging \\ 13 April 2013 \\ Number of times this article has been viewed
}

\section{Shihui Fu \\ Leiming Luo \\ Ping Ye \\ Shuangyan Yi \\ Yuan Liu \\ Bing Zhu \\ Liang Wang \\ Tiehui Xiao \\ Yongyi Bai}

Department of Geriatric Cardiology, Chinese PLA General Hospital,

Beijing, People's Republic of China
Correspondence: Leiming Luo

Department of Geriatric Cardiology,

Chinese PLA General Hospital,

28 Fuxing Road, Haidian District,

Beijing 100853, People's Republic

of China

Tel +8610 88626362

Email lleim@sina.com
Objective: To analyze the relationship between N-terminal pro-brain natriuretic peptide (NT-proBNP) and renal function, and compare the ability and cut-off thresholds of NT-proBNP to detect chronic heart failure (CHF) and predict mortality in elderly Chinese coronary artery disease (CAD) patients with and without chronic kidney disease (CKD).

Methods: The study included 999 CAD patients older than 60 years. The endpoint was all-cause mortality over a mean follow-up period of 417 days.

Results: The median age was 86 years (range: 60-104 years), and the median NT-proBNP level was $409.8 \mathrm{pg} / \mathrm{mL}$. CKD was present in 358 patients. Three hundred and six patients were positive for CHF. One hundred and ten CKD patients and 105 non-CKD patients died. Not only CKD, but also estimated glomerular filtration rate independently affected NT-proBNP. NT-proBNP detected CHF with a cut-off value of $298.4 \mathrm{pg} / \mathrm{mL}$ in non-CKD patients and a cut-off value of $435.7 \mathrm{pg} / \mathrm{mL}$ in CKD patients. NT-proBNP predicted death with a cut-off value of $369.5 \mathrm{pg} / \mathrm{mL}$ in non-CKD patients and a cut-off value of $2584.1 \mathrm{pg} / \mathrm{mL}$ in CKD patients. The NT-proBNP level was significantly related to the prevalence of CHF and all-cause mortality in CAD patients with and without $\mathrm{CKD}$; this effect persisted after adjustment. The crude and multiple adjusted hazard ratios of NT-proBNP to detect $\mathrm{CHF}$ and predict mortality were significantly higher in patients with CKD compared with the remainder of the population. The addition of NT-proBNP to the three-variable and six-variable models generated a significant increase in the C-statistic.

Conclusion: Amongst elderly Chinese CAD patients, there was an independently inverse association between NT-proBNP and renal function. With the higher cutoff points, NT-proBNP better detected CHF and better predicted mortality in CKD patients than in non-CKD patients.

Keywords: aged, coronary artery disease, chronic kidney disease, N-terminal pro-brain natriuretic peptide, prognosis

\section{Introduction}

N-terminal pro-brain natriuretic peptide (NT-proBNP) is a well-known biomarker for cardiovascular diseases, including heart failure (HF) and coronary artery disease (CAD), and may facilitate the early diagnosis of acute HF (AHF) and stratification of cardiac risk. ${ }^{1}$ Chronic kidney disease (CKD) is a common comorbidity that affects a significant portion of patients with cardiovascular diseases. ${ }^{2,3}$ Similarly, CKD patients are at increased risk of suffering from cardiovascular complications. ${ }^{46}$ Therefore, patients with known or suspected CAD and HF, as well as CKD patients, are potential candidates for NT-proBNP testing. Understanding the influence of renal function 
on the NT-proBNP level is thus highly relevant for clinical application. As the NT-proBNP level is more frequently utilized, there has been much debate over the interpretation and significance of the NT-proBNP level in CKD patients. ${ }^{1}$ Indeed, although several studies have provided clear and convincing evidence of the diagnostic value of NT-proBNP for AHF, ${ }^{1}$ the ability of NT-proBNP to detect patients with chronic HF (CHF) and the appropriate cutoff values have not been tested in a sufficient number of CAD patients with and without CKD. ${ }^{7}$ In addition, previous studies have examined the prognostic usefulness of NT-proBNP in HF patients with and without $\mathrm{CKD},{ }^{8,9}$ but studies focusing on the prognostic impact in CAD patients with concomitant CKD are limited. Moreover, in elderly patients, data illustrating the relationship between renal function and NT-proBNP level and relating the detecting and prognostic role of NT-proBNP level to renal function is scarce, especially in the People's Republic of China. To be of clinical value, NT-proBNP measurements need to be evaluated within the context of renal function in elderly patients. Thus, the current study attempted to investigate the serum NT-proBNP levels of patients with varying levels of renal function, and compare the roles and cutoff values of NT-proBNP to detect CHF and predict mortality in elderly Chinese CAD patients with and without CKD.

\section{Methods}

\section{Study population}

Initially, this prospective study included 1050 CAD inpatients older than 60 years from October 11, 2007 to July 2, 2011. The Chinese PLA General Hospital was their designated hospital and had the integrated long-term medical and final death records of the patients, which made it easier for us to follow-up effectively and judge endpoints accurately. The diagnosis of CAD was supported by history, symptoms of typical angina, cardiac markers, and specific cardiac examinations, such as electrocardiogram (resting/ exercise), echocardiography, radionuclide imaging, computed tomography, and coronary angiography, as established by chief physicians on the basis of the American College of Cardiology (ACC)/American Heart Association (AHA) or European Society of Cardiology (ESC) guidelines. ${ }^{10-12}$ Serum NT-proBNP was not obtained in a total of 51 patients. Thus, 999 patients were eligible for analysis.

\section{Measurements and definitions}

Serum NT-proBNP was measured by the NT-proBNP Flex Reagent Cartridge (PBNP/LPBN) produced by Siemens Healthcare Diagnostics Inc (Deerfield, IL, USA) on the
Dimension RxL Max (analytical measurement range: 10-30,000 pg/mL; Siemens Healthcare Global, Erlangen, Germany). Body mass index (BMI) was defined as weight in kilograms divided by the square of height in meters. Mean systolic blood pressure (MSBP) and mean diastolic blood pressure (MDBP) were taken as the average of five separate measurements. Conventional echocardiogram was performed and the ejection fraction (EF) was obtained. Estimated glomerular filtration rate (eGFR) was calculated by a modified Modification of Diet in Renal Disease (MDRD) equation based on data from Chinese CKD patients: ${ }^{13}$

$$
\begin{aligned}
& 175 \times \text { serum creatinine }(\mathrm{mg} / \mathrm{dL})^{-1.234} \\
& \times \text { age }(\text { year })^{-0.179}(\times 0.79 \text { if female })
\end{aligned}
$$

CKD was defined as eGFR $<60 \mathrm{~mL} /$ minute $/ 1.73 \mathrm{~m}^{2}$ on the basis of the Kidney Disease Outcomes Quality Initiative (KDOQI) Working Group definition. ${ }^{14}$ Atrial fibrillation (AF) and $\mathrm{CHF}$ were diagnosed by chief physicians according to the ACC/AHA/ESC guidelines for $\mathrm{AF}^{15}$ and the ESC guidelines for CHF. ${ }^{16}$ Patients with a MSBP $\geq 140 \mathrm{mmHg}$, $\mathrm{MDBP} \geq 90 \mathrm{mmHg}$ or patients receiving medication for treatment of hypertension (HTN) were defined as having HTN. Patients with a fasting glucose concentration $\geq 7 \mathrm{mmol} / \mathrm{L}$ or receiving treatment with an oral hypoglycemic agent/ insulin were defined as having diabetes mellitus (DM). If the hemoglobin level was lower than $120 \mathrm{~g} / \mathrm{L}$ in males or $110 \mathrm{~g} / \mathrm{L}$ in females, the diagnosis of anemia was established. Hypoalbuminemia was considered to be present if patients had a serum albumin $<30 \mathrm{~g} / \mathrm{L}$. The diagnosis of hyperuricemia was made if the patients met the following criterion: uric acid $>420$ umol/L for males or $>350$ umol/L for females.

\section{Traditional prognostic models}

In spite of many models predicting renal replacement therapy, there are few models to forecast mortality for patients with CKD. The most basic and simple risk assessment model of CKD consists of age, gender, and eGFR (three-variable model). Meanwhile, the six-variable model includes age, gender, eGFR, DM, HTN, and anemia, and has been reported to have a greater ability to estimate CKD mortality. ${ }^{17}$

\section{End point}

Given the high incidence of multiple organ failure in the elderly as well as the priority of all-cause mortality in outcome studies, the primary endpoint assessed in the current study was all-cause death. The study population had a mean follow-up period of 417 days (median: 317 days; 75\% range: 185-557 days). No patient was dropped during the study 
period. Follow-up data was obtained from medical records and telephone contact. Death was ascertained from death record; a legal document including time, site, and other information.

\section{Statistical methods}

Continuous variables were described using mean and standard deviation for data with a normal distribution, and median and $75 \%$ range for non-normally distributed variables. Categorical data were expressed as a percentage of the total. The correlation between the NT-proBNP level and other variables was determined by Spearman rank correlation coefficients. The NT-proBNP level was logarithmically transformed to meet the multinormality assumption. The multiple linear regression model with NT-proBNP as the dependent variable was used to determine independent determinants of NT-proBNP. Receiver-operating characteristic curves and area under the curve ( $\mathrm{C}$ statistics) were used to assess the usefulness of NT-proBNP to identify $\mathrm{CHF}$ or predict death. The added predictive abilities of NTproBNP to CKD risk assessment models regarding mortality were investigated by comparison of C-statistics between models and models + NT-proBNP. The Z-statistic was used to compare the C-statistics. To examine the ability of NT-proBNP in detecting CHF, the multivariate logistic regression model with $\mathrm{CHF}$ as a dependent variable was developed. To test prognostic values of NT-proBNP for mortality, the multivariate Cox regression model with death as the dependent variable was used. Differences in hazard ratios (HRs) between patients with CKD and without CKD were checked with interaction analysis. Survival curves were generated by means of Kaplan-Meier estimates. A two-tailed $P$-value of less than 0.05 was considered to be statistically significant. There was little missing data; in the cases where date was missing, the missing values were calculated by multiple imputations and the results were pooled to minimize bias. ${ }^{18}$ All information on the characteristics of patients was entered into the database by trained abstractors and checked by other independent abstractors. SPSS 17 (SPSS Inc., Chicago, IL, USA) and MedCalc 9.6 for Windows (MedCalc Software bvba, Ostend, Belgium) were used as the statistical systems.

\section{Results}

\section{Independent impact of cardiac factors and renal function on the NT-proBNP level}

At baseline, the median age of the study patients was 86 years (range: $60-104$ years) and the median NT-proBNP level was $409.8 \mathrm{pg} / \mathrm{mL}(158.4-1783.8 \mathrm{pg} / \mathrm{mL})$. Table 1 displays descriptive statistics of the study population. CKD was present in 358 patients (35.8\%), who had a significantly higher NT-proBNP concentration (median NT-proBNP level: $1027.5 \mathrm{pg} / \mathrm{mL}$ [267.3-3660.5 pg/mL]) than patients without CKD (median NT-proBNP level: $298.6 \mathrm{pg} / \mathrm{mL}$ [129.1-950.2 pg/mL] $)(P<0.001)$. There were even significant distinctions in NT-proBNP level between patients in different stages of CKD (eGFR 45-60 mL/minute/1.73 m² $526.3 \mathrm{pg} / \mathrm{mL}$ [174.9-1915.4 pg/mL]; eGFR 30-45 mL/ minute $/ 1.73 \mathrm{~m}^{2}: 1531.0 \mathrm{pg} / \mathrm{mL}$ [518.6-3755.6 pg/mL]; eGFR $<30 \mathrm{~mL} /$ minute $/ 1.73 \mathrm{~m}^{2}: 4734.7 \mathrm{pg} / \mathrm{mL}[1357.0$ $19163.0 \mathrm{pg} / \mathrm{mL}$ ]; all $P<0.001$ ). The NT-proBNP levels in all of the patients had a strong inverse association with eGFR (correlation coefficient, $-0.319, P<0.001$ ). After adjusting for age; gender; BMI; acute myocardial infarction (AMI); CHF; HTN; DM; AF; anemia; hypoalbuminemia; hyperuricemia; MSBP; heart rate; $\mathrm{EF}<40 \%$; serum $\mathrm{Na}^{+}, \mathrm{Ka}^{+}$, and $\mathrm{Ca}^{2+}$ levels; and diuretic use, not only CKD and eGFR < $45 \mathrm{~mL} /$ minute $/ 1.73 \mathrm{~m}^{2}$, but also the eGFR level as a continuous variable (all $P<0.001$ ) had an independent influence on the NT-proBNP level. Other independently associated factors were age, BMI, AMI, CHF, AF, anemia, hypoalbuminemia, heart rate, $\mathrm{EF}<40 \%$, and serum $\mathrm{Ka}^{+}$and $\mathrm{Ca}^{2+}$ levels (all $P<0.05$ ). BMI and serum $\mathrm{Ca}^{2+}$ had a negative correlation with NT-proBNP level; all other factors had a positive correlation with NT-proBNP level. The impact of CKD on the NT-proBNP level ( $\beta$ value: 0.135) was less than the impact of cardiac factors (CHF, AMI, AF, and $\mathrm{EF}<40 \%$ ) and anemia, whereas the impact of eGFR $<45 \mathrm{~mL} /$ minute $/ 1.73 \mathrm{~m}^{2}$ on the NT-proBNP level ( $\beta$ value: 0.228 ) was higher than these factors. No significant correlation was noted between the NTproBNP level and gender, HTN, DM, hyperuricemia, MSBP, serum $\mathrm{Na}^{+}$level, and diuretic use (all $P>0.05$ ).

\section{Superior ability of NT-proBNP to detect $\mathrm{CHF}$ in CKD patients}

Of 999 eligible patients, 306 (30.6\%) were positive for CHF. The NT-proBNP level was significantly related to the prevalence of CHF in CAD patients with CKD (crude HR: 1.728, 95\% confidence interval [CI]: 1.487-2.007, $P<0.001)$ and without CKD (crude HR: 1.727, 95\% CI: 1.510-1.977, $P<0.001$ ), and the significance persisted after adjusting for age; gender; BMI; AMI; HTN; DM; AF; anemia; hypoalbuminemia; hyperuricemia; MSBP; heart rate; $\mathrm{EF}<$ $40 \%$; serum $\mathrm{Na}^{+}, \mathrm{Ka}^{+}$, and $\mathrm{Ca}^{2+}$ levels; and diuretic use (with CKD: adjusted HR: 1.707, 95\% CI: 1.415-2.061, $P<0.001$; without CKD: adjusted HR: 1.474, 95\% CI: 1.202-1.806, 
Table I Baseline characteristics of study population

\begin{tabular}{|c|c|c|c|c|}
\hline \multirow[t]{2}{*}{ Variables } & \multirow{2}{*}{$\begin{array}{l}\text { No CKD } \\
(n=64 I)\end{array}$} & \multicolumn{2}{|c|}{ CKD $(n=358)$} & \multirow{2}{*}{$\begin{array}{l}\text { Total } \\
(n=999)\end{array}$} \\
\hline & & $\begin{array}{l}\text { eGFR } 45-60 \mathrm{~mL} / \\
\text { minute } / 1.73 \mathrm{~m}^{2} \\
(\mathrm{n}=194)\end{array}$ & $\begin{array}{l}\text { eGFR }<45 \mathrm{~mL} / \\
\text { minute/l.73 } \mathrm{m}^{2} \\
(\mathrm{n}=\mathrm{I} 64)\end{array}$ & \\
\hline \multicolumn{5}{|l|}{ Demographics } \\
\hline Age (years) median ( $75 \%$ range) & $85(81-89)$ & $86(83-90)$ & $87(82-91)$ & $86(82-90)$ \\
\hline Males $(\%)$ & $592(92.4)$ & $172(88.7)$ & $140(85.4)$ & $904(90.5)$ \\
\hline BMI $\left(\mathrm{kg} / \mathrm{m}^{2}\right)$ mean (SD) & $23.8(3.4)$ & $24.4(3.4)$ & $23.4(3.6)$ & $23.9(3.5)$ \\
\hline \multicolumn{5}{|l|}{ Diseases } \\
\hline AMI (\%) & $35(5.5)$ & $16(8.2)$ & $20(12.2)$ & $71(7.1)$ \\
\hline $\mathrm{CHF}(\%)$ & 147 (22.9) & $72(37.1)$ & $87(53.0)$ & $306(30.6)$ \\
\hline HTN (\%) & $489(76.3)$ & $165(85.1)$ & $14 \mid(86.0)$ & $795(79.6)$ \\
\hline DM (\%) & $242(37.8)$ & $8 I(4 I .8)$ & $73(44.5)$ & $396(39.6)$ \\
\hline $\mathrm{AF}(\%)$ & $125(19.5)$ & $54(27.8)$ & $34(20.7)$ & $213(21.3)$ \\
\hline Anemia $(\%)$ & $203(31.7)$ & $87(44.8)$ & $115(70.1)$ & $405(40.5)$ \\
\hline Hypoalbuminemia (\%) & $23(3.6)$ & $3(1.5)$ & $19(11.6)$ & $45(4.5)$ \\
\hline Hyperuricemia (\%) & $100(15.6)$ & $76(39.2)$ & $91(55.5)$ & $267(26.7)$ \\
\hline \multicolumn{5}{|l|}{ Clinical presentation } \\
\hline $\operatorname{MSBP}(\mathrm{mmHg})$ mean $(\mathrm{SD})$ & $132.6(13.5)$ & | $33.7(\mid 2.8)$ & $134.9(13.6)$ & $132.3(|23.6-| 42.0)$ \\
\hline HR (bpm) median (75\% range) & $72(64-80)$ & $70(64-80)$ & $74(65-83)$ & $72(64-80)$ \\
\hline \multicolumn{5}{|l|}{ Investigative variables } \\
\hline $\mathrm{EF}<40 \%(\%)$ & $14(2.2)$ & $9(4.6)$ & $13(7.9)$ & $36(3.6)$ \\
\hline \multicolumn{5}{|l|}{ Laboratory results } \\
\hline NT-proBNP (pg/mL) median (75\% range) & $298.6(\mid 29.1-950.2)$ & $526.3(174.9-19 \mid 5.4)$ & $2390.8(749.2-7397.8)$ & $409.8(158.4-1783.8)$ \\
\hline eGFR $\left(\mathrm{mL} /\right.$ minute $\left./ \mathrm{l} .73 \mathrm{~m}^{2}\right)$ median (75\% range) & $78.7(70.0-89.2)$ & $53.9(50.8-57.2)$ & $33.9(19.8-39.7)$ & $68.7(53.1-82.3)$ \\
\hline $\mathrm{Na}^{+}(\mathrm{mmol} / \mathrm{L})$ median $(75 \%$ range $)$ & $139(136-142)$ & $139(136-142)$ & $139(135-142)$ & $139(136-142)$ \\
\hline $\mathrm{Ka}^{+}(\mathrm{mmol} / \mathrm{L})$ median $(75 \%$ range $)$ & $3.9(3.7-4.2)$ & $4.0(3.8-4.3)$ & $4.2(3.9-4.6)$ & $4.0(3.7-4.3)$ \\
\hline $\mathrm{Ca}^{2+}(\mathrm{mmol} / \mathrm{L})$ median (75\% range) & $2.2(2.1-2.3)$ & $2.2(2.1-2.3)$ & $2.3(2.1-2.4)$ & $2.2(2.1-2.3)$ \\
\hline \multicolumn{5}{|l|}{ Drug } \\
\hline Diuretic use (\%) & $529(82.5)$ & $194(100.0)$ & $164(100.0)$ & $887(88.8)$ \\
\hline
\end{tabular}

Abbreviations: AF, atrial fibrillation; AMI, acute myocardial infarction; BMI, body mass index; CHF, chronic heart failure; CKD, chronic kidney disease; DM, diabetes mellitus; EF, ejection fraction; eGFR, estimated glomerular filtration rate; HR, heart rate; HTN, hypertension; MSBP, mean systolic blood pressure; NT-proBNP, N-terminal pro-brain natriuretic peptide; SD, standard deviation.

$P<0.001)$. By interaction analysis, the crude $\mathrm{HR}$ values (1.728 versus $1.727, P<0.001)$ and multiple adjusted HR values $(1.707$ versus $1.474, P=0.002)$ of NT-proBNP were significantly higher in patients with CKD compared with the remainder of the population.

In patients without CKD, NT-proBNP detected CHF with a C-statistic of 0.720 (95\% CI: $0.671-0.769, P<0.001)$ and a cutoff value of $298.4 \mathrm{pg} / \mathrm{mL}$ (Figure 1A). In patients with CKD, NT-proBNP detected CHF with a C-statistic of 0.749 (95\% CI: 0.689-0.799, $P<0.001)$ and a cutoff value of 435.7 $\mathrm{pg} / \mathrm{mL}$ (Figure 1B). The C-statistic for NT-proBNP in detecting CHF in patients with CKD was higher (but not significant) than in patients without $\mathrm{CKD}(0.749$ versus $0.720, P=0.421)$. In patients without $\mathrm{CKD}, \mathrm{CHF}$ was more common in patients with a NT-proBNP level $>298.4 \mathrm{pg} / \mathrm{mL}$ in comparison to patients with a NT-proBNP level $<298.4 \mathrm{pg} / \mathrm{mL}$ (HR: 4.790, 95\% CI: $3.126-7.338, P<0.001)$. In CKD patients, the likelihood of CHF was significantly higher in patients with a NT-proBNP level $>435.7 \mathrm{pg} / \mathrm{mL}$ in comparison to patients with a NT-proBNP level $<435.7 \mathrm{pg} / \mathrm{mL}$ (HR: 8.750, 95\% CI: $4.978-15.380, P<0.001)$.

\section{Superior independent and compensated prognostic ability of NT-proBNP in CKD patients}

One hundred and ten patients $(30.7 \%)$ with CKD and 105 patients $(16.4 \%)$ without CKD died during the follow-up period. The NT-proBNP level was significantly related to all-cause death in CAD patients with CKD (crude HR: 1.766, 95\% CI: $1.574-1.983, P<0.001$ ) and without CKD (crude HR: 1.691, 95\% CI: 1.504-1.901, $P<0.001$ ), and the significance persisted after adjusting for age; gender; BMI; AMI; CHF; HTN; DM; AF; anemia; hypoalbuminemia; hyperuricemia; MSBP; heart rate; EF $<40 \%$; serum $\mathrm{Na}^{+}, \mathrm{Ka}^{+}$, and $\mathrm{Ca}^{2+}$ levels; and diuretic use (with CKD: adjusted HR: 1.542, 95\% CI: 1.324-1.795, $P<0.001$; without CKD: adjusted HR: 1.384 , 95\% CI: $1.190-1.609, P<0.001)$. By interaction analysis, the 

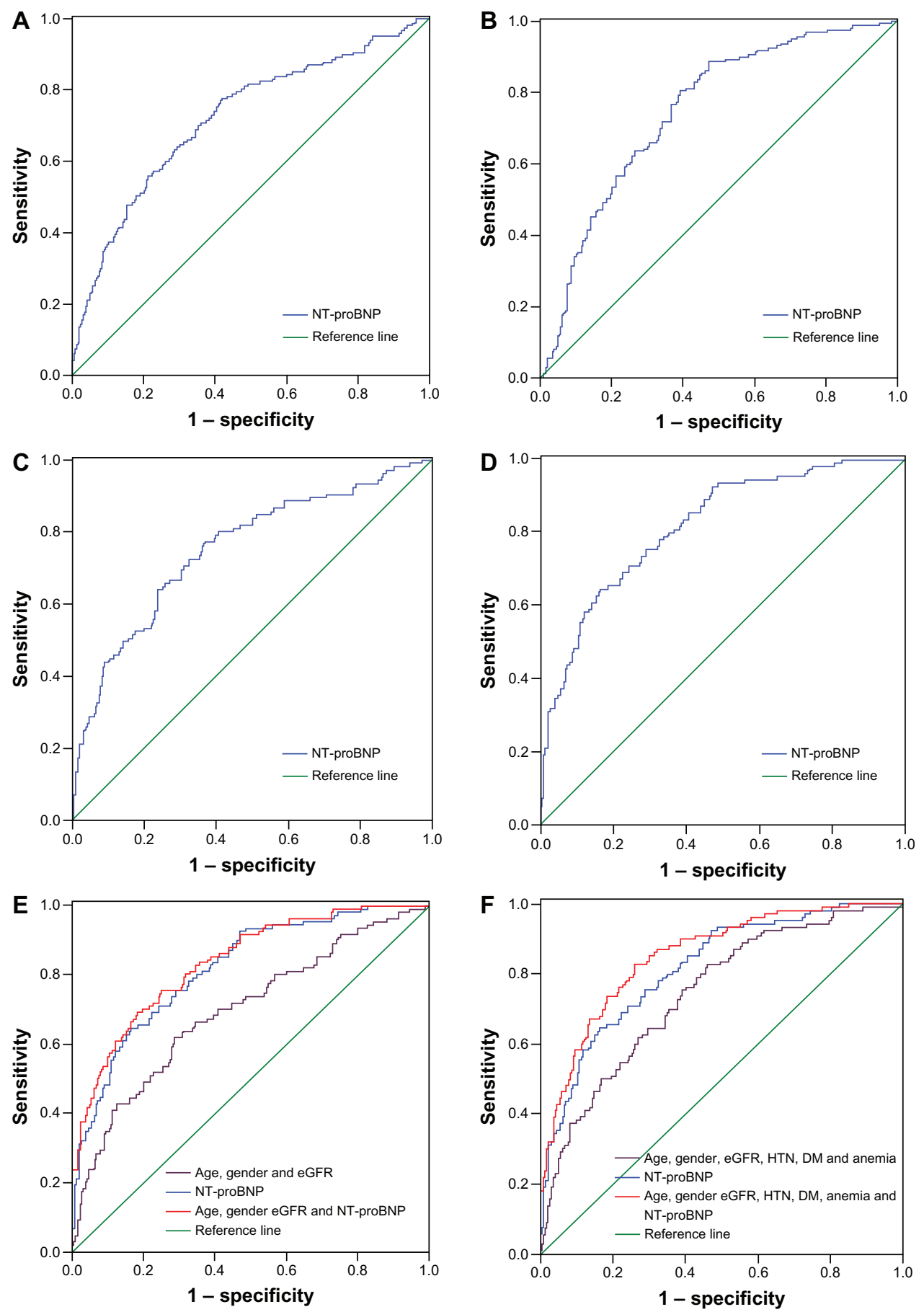

Figure I (A) Non-CKD patients ( $n=641)$ : ROC curve analysis for NT-proBNP identifying CHF. (B) CKD patients $(n=358)$ : ROC curve analysis for NT-proBNP identifying CHF. (C) non-CKD patients $(n=641)$ : ROC curve analysis for NT-proBNP predicting death. (D) CKD patients $(n=358)$ : ROC curve analysis for NT-proBNP predicting death. (E) CKD patients $(n=358)$ : comparison of ROC curve predicting death between NT-proBNP and the three-variable model. $(\mathbf{F})$ CKD patients $(n=358)$ : comparison of ROC curve predicting death between NT-proBNP and the six-variable model.

Abbreviations: CHF, chronic heart failure; CKD, chronic kidney disease; DM, diabetes mellitus; eGFR, estimated glomerular filtration rate; HTN, hypertension; NTproBNP, N-terminal pro-brain natriuretic peptide; ROC, receiver-operating characteristic.

crude HR values (1.766 versus $1.691, P<0.001)$ and multiple adjusted HR values (1.542 versus $1.384, P=0.008$ ) of NT-proBNP were significantly higher in patients with CKD compared with the remainder of the population. Meanwhile, patients with different stages of CKD were analyzed separately. With the deterioration of CKD, the crude HRs (eGFR $>45 \mathrm{~mL} /$ minute $/ 1.73 \mathrm{~m}^{2}$ : HR: 2.051, 95\% CI: $1.609-2.615$; eGFR $30-45 \mathrm{~mL} /$ minute $/ 1.73 \mathrm{~m}^{2}$ : HR: $1.716 ; 95 \%$ CI: $1.340-2.198$; eGFR $<30 \mathrm{~mL} /$ minute/1.73 $\mathrm{m}^{2}$ : HR: $1.574 ; 95 \%$ CI: $1.253-1.978$; 
all $P<0.001)$ and multiple adjusted HRs (eGFR $>45 \mathrm{~mL} /$ minute/1.73 $\mathrm{m}^{2}$ : HR: 2.075, 95\% CI: 1.462-2.945; eGFR 30-45 mL/minute/1.73 m²: HR: 1.922 ; 95\% CI: $1.288-$ 2.870; eGFR < $30 \mathrm{~mL} / \mathrm{minute} / 1.73 \mathrm{~m}^{2}$ : HR: 1.729; $95 \%$ CI: 1.189-2.515; all $P<0.05$ ) of NT-proBNP decreased. Of note, regardless of the stage of CKD, NT-proBNP was an independent predictor of all-cause mortality in these patients. The crude and multiple adjusted influences of NT-proBNP on mortality are listed in Table 2.

NT-proBNP predicted death with a C-statistic of 0.751 (95\% CI: $0.698-0.805, P<0.001)$ in patients without CKD (Figure 1C) and a C statistic of 0.818 (95\% CI: 0.772-0.864, $P<0.001$ ) in patients with CKD (Figure 1D). The C-statistic for NT-proBNP in predicting death in patients with CKD was higher (but not significant) than in patients without CKD (0.818 versus $0.751, P=0.064)$. The cutoff value of NT-proBNP that best distinguished the deaths versus the survivors amongst patients with CKD (2584.1 pg/mL) was approximately six times higher than the NT-proBNP cutoff value amongst patients without CKD (369.5 pg/mL). In addition, there was a significantly worse prognosis in patients with a NT-proBNP level greater than the cutoff value compared with patients with a NT-proBNP level less than cutoff value (with CKD: HR: 5.304, 95\% CI: 3.582-7.853; without CKD: HR: 5.152, 95\% CI: 3.264-8.130; all $P<0.001$ ). KaplanMeier analyses based on the two cutoff values provided better descriptions (Figure 2A and B).

The analyses of the compensated predictive roles of NT-proBNP to the risk assessment models of CKD were confined to patients with $\mathrm{CKD}$. The C-statistic of the NTproBNP level in predicting death in patients with $\mathrm{CKD}$ was statistically greater than the three-variable $(0.818$ versus $0.694, P<0.001)$ and six-variable models $(0.818$ versus $0.744, P=0.035$ ) (Table 3 , Figure $1 \mathrm{E}$ and $\mathrm{F}$ ). The addition of the NT-proBNP level to the three-variable $(0.836$ versus $0.694, P<0.001)$ and six-variable models $(0.853$ versus
0.744, $P<0.001)$ generated a significant increase in the C-statistic (Table 3).

\section{Discussion \\ Independent impact of cardiac factors and renal function on the NT-proBNP level}

The current study showed an inverse, significant, and independent correlation between the NT-proBNP level and eGFR in elderly CAD patients with and without CKD. This finding corroborated recent observational studies that indicated a relationship between NT-proBNP and eGFR in patients with stable ischemic heart disease, ${ }^{19}$ peripheral artery disease, ${ }^{20}$ $\mathrm{HF}^{21}$ and acute dyspnea, ${ }^{1}$ and in patients with various stages of renal function; ${ }^{4,22}$ this finding was in contrast to pooled data which suggested that there was no interdependence between renal impairment and increased NT-proBNP concentration. ${ }^{23}$ The correlation coefficients between NT-proBNP and eGFR typically ranged from -0.3 to -0.5 , which were in agreement with our result $(-0.319)$. The current study illustrated that the cause of an elevated NT-proBNP level was multifactorial and reflected the changes in cardiac and renal function. To what extent the increase in the NT-proBNP level was due to decreased renal clearance versus increased cardiac production is controversial. Previous assessments have tempered the enthusiasm to conclude that cardiac pathology is the primary etiology of an increase in NT-proBNP level. For example, van Kimmenade et al proposed that an increased NT-proBNP level was predominantly related to, and a result of, the presence and extent of cardiac pathology rather than impaired renal clearance. ${ }^{24}$ The current study showed that when eGFR was between $45-60 \mathrm{~mL} /$ minute $/ 1.73 \mathrm{~m}^{2}$, the NT-proBNP level was most strongly dependent on cardiovascular diseases, such as CHF, AMI, and AF, as well as cardiac function $(\mathrm{EF})$ rather than renal function, which was

Table 2 Hazard ratios of NT-proBNP in elderly Chinese coronary artery disease patients with and without CKD

\begin{tabular}{|c|c|c|c|c|}
\hline Alla & $\begin{array}{l}\text { Crude HR } \\
(95 \% \mathrm{Cl})\end{array}$ & $P$-value & $\begin{array}{l}\text { Multiple adjusted } \\
\text { HR }(95 \% \mathrm{Cl})^{\mathrm{b}}\end{array}$ & $P$-value \\
\hline No CKD & $1.691(1.504-1.901)$ & $<0.001$ & $1.384(1.190-1.609)$ & $<0.001$ \\
\hline $\mathrm{CKD}^{c}$ & $1.766(1.574-1.983)$ & $<0.001$ & $1.542(1.324-1.795)$ & $<0.001$ \\
\hline eGFR $>45 \mathrm{~mL} /$ minute $/ \mathrm{l} .73 \mathrm{~m}^{2}$ & $2.051(1.609-2.615)$ & $<0.001$ & $2.075(1.462-2.945)$ & $<0.001$ \\
\hline eGFR $30-45 \mathrm{~mL} /$ minute $/ 1.73 \mathrm{~m}^{2}$ & $1.716(1.340-2.198)$ & $<0.001$ & $1.922(1.288-2.870)$ & 0.001 \\
\hline eGFR $<30 \mathrm{~mL} /$ minute/l.73 $\mathrm{m}^{2}$ & $1.574(1.253-1.978)$ & $<0.001$ & $1.729(1.189-2.515)$ & 0.004 \\
\hline
\end{tabular}

Notes: ${ }^{a}$ Cox regression all-cause mortality analyses; badjusted for age, gender, body mass index, acute myocardial infarction, chronic heart failure, hypertension, diabetes mellitus, atrial fibrillation, anemia, hypoalbuminemia, hyperuricemia, mean systolic blood pressure, heart rate, ejection fraction $<40 \%, \mathrm{Na}^{+}, \mathrm{Ka}^{+}$, and $\mathrm{Ca}^{2+}$ levels, and diuretic use; 'separate analyses for patients with CKD and different stages of CKD.

Abbreviations: CKD, chronic kidney disease; Cl, confidence interval; eGFR, estimated glomerular filtration rate; HR, hazard ratio; NT-proBNP, N-terminal pro-brain natriuretic peptide. 

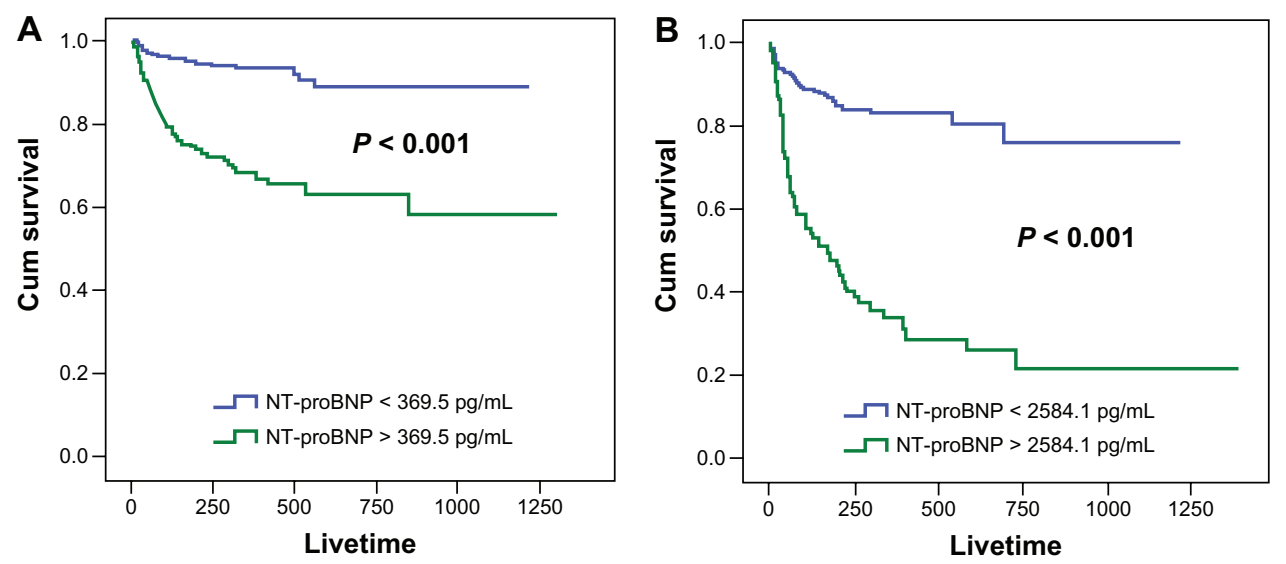

Figure 2 (A) Non-CKD patients $(n=64 I)$ : Kaplan-Meier estimate of survival according to the cutoff point of NT-proBNP $(369.5$ pg/mL). $($ B) CKD patients $(n=358)$ : Kaplan-Meier estimate of survival according to the cutoff point of NT-proBNP $(2584.1 \mathrm{pg} / \mathrm{mL})$.

Abbreviations: CKD, chronic kidney disease; NT-proBNP, N-terminal pro-brain natriuretic peptide.

in agreement with previous reports. But when eGFR was $<45 \mathrm{~mL} /$ minute $/ 1.73 \mathrm{~m}^{2}$, renal function was crucial for the change in the NT-proBNP level, rather than cardiac function and cardiovascular diseases.

\section{Superior ability of NT-proBNP to detect $\mathrm{CHF}$ in CKD patients}

Several studies have provided clear and convincing evidence of the diagnostic value of NT-proBNP for AHF, ${ }^{1}$ but there was a lack of clear recommendations regarding its relationship with CHF and CKD. The issue of how to differentially interpret the $\mathrm{CHF}$ detecting utilities of the NT-proBNP level within the context of renal function has received considerable attention and has been tested in a small population but remains incompletely resolved from a clinical perspective. When comparing the detecting ability of the NT-proBNP

Table 3 Prognostic value of NT-proBNP and other models in elderly Chinese patients with both coronary artery disease and chronic kidney disease

\begin{tabular}{llll}
\hline & C statistic $(\mathbf{9 5 \%} \mathbf{C l})$ & Z value & P-value \\
\hline NT-proBNP & $0.818(0.774-0.857)$ & & \\
Age, gender, and eGFR & $0.694(0.644-0.74 \mathrm{I})$ & 3.483 & $<0.00 \mathrm{I}^{\mathrm{a}}$ \\
$\begin{array}{l}\text { Age, gender, and eGFR } \\
\text { plus NT-proBNP }\end{array}$ & $0.836(0.793-0.873)$ & 4.735 & $<0.00 \mathrm{I}^{\mathrm{b}}$ \\
$\begin{array}{l}\text { Age, gender, eGFR, } \\
\text { DM, HTN, and anemia }\end{array}$ & $0.744(0.696-0.788)$ & 2.112 & $0.035^{\mathrm{a}}$ \\
$\begin{array}{l}\text { Age, gender, eGFR, } \\
\text { DM, HTN, and anemia } \\
\text { plus NT-proBNP }\end{array}$ & $0.853(0.8 \mathrm{II}-0.888)$ & 4.162 & $<0.00 \mathrm{I}^{\mathrm{b}}$ \\
\hline
\end{tabular}

Notes: ${ }^{a}$-value was drawn from comparisons between other models and NTproBNP; ${ }^{b} P$-value was drawn from comparisons between other models with the addition of NT-proBNP and other models.

Abbreviations: $\mathrm{Cl}$, confidence interval; DM, diabetes mellitus; eGFR, estimated glomerular filtration rate; HTN, hypertension; NT-proBNP, N-terminal-pro-brain natriuretic peptide. level in individuals with and without deteriorating renal function, previous studies reported that only mildly diminished accuracy was observed in renal disease as long as a modestly increased optimal cutoff value was used for NT-proBNP. ${ }^{25}$ The current study, which focused on elderly patients with CAD, showed that the usefulness of NT-proBNP in detecting CHF in the presence of CKD might be improved to some extent rather than compromised after adopting a higher cutoff value.

\section{Superior independent and compensated prognostic ability of NT-proBNP in CKD patients}

NT-proBNP has been reported to be a significant predictor of mortality for cardiovascular diseases such as $\mathrm{HF}$ and $\mathrm{CAD}^{26,27}$ The prognoses of CKD patients based on the NTproBNP level have not been thoroughly studied; indeed, only small series have shown the ability of NT-proBNP to independently predict adverse outcomes. ${ }^{8}$ Previous studies have shown that NT-proBNP provides independent and similar prognostic information in the entire CHF cohort, as well as in subgroups with and without CKD. ${ }^{8,9}$ Given the increasing number of patients affected by both CAD and CKD, the effect of CKD on the application of NT-proBNP in risk stratification of CAD patients is of particular importance. However, there has been no study definitively answering the question of whether or not the NT-proBNP level has an important prognostic role in the CAD population with and without CKD, especially in elderly patients. The current study confirmed the superior independent predictive performance of NT-proBNP in elderly CAD patients with $\mathrm{CKD}$ in comparison to patients without CKD. Moreover, when suitable cutoff points of NT-proBNP were used, 
low- and high-risk subpopulations could easily be identified in both patients with CKD and patients without CKD. Nevertheless, there was an obviously higher cutoff value in the CKD patients than in the non-CKD patients. Currently most institutions continue to use the NT-proBNP diagnostic and prognostic cutoff levels without taking renal function into account. Our data emphasizes that the cutoff values of NT-proBNP must be evaluated in conjunction with the overall status of patients, particularly the level of renal function. Additionally, the current study described the additive effects of NT-proBNP on CKD risk assessment models, ie, the compensated predictive ability of NT-proBNP.

The current study had several limitations. Firstly, due to the shortage of noninvasive methods and unified standards in evaluating blood volume, there was no other invasive data about blood volume except for blood pressure in our study. In addition, the sample size of our study is relatively small, and there is need of large studies to confirm our study results.

The following conclusions about elderly Chinese patients could been drawn from the current study: (1) a significantly and independently inverse association between NT-proBNP level and renal function was evident, with higher NT-proBNP level observed as eGFR declined; (2) NT-proBNP was shown to have a better ability to detect $\mathrm{CHF}$ and predict mortality in CKD patients than in non-CKD patients; (3) CKD patients had higher cutoff points for NT-proBNP in detecting CHF or predicting death than non-CKD patients; and (4) NT-proBNP added important information to CKD risk assessment models in patients with CAD.

\section{Acknowledgment}

This study was supported by the Central Health Special Foundation (grant number B2009B108) and The National Key Basic Research Project (973) (grant number CB517503) (Beijing, People's Republic of China).

\section{Disclosure}

The authors report no conflicts of interest in this work.

\section{References}

1. Januzzi JL Jr, Camargo CA, Anwaruddin S, et al. The N-terminal ProBNP Investigation of Dyspnea in the Emergency department (PRIDE) study. Am J Cardiol. 2005;95(8):948-954.

2. Anavekar NS, McMurray JJ, Velazquez EJ, et al. Relation between renal dysfunction and cardiovascular outcomes after myocardial infarction. N Engl J Med. 2004;351(13):1285-1295.

3. McAlister FA, Ezekowitz J, Tonelli M, Armstrong PW. Renal insufficiency and heart failure: prognostic and therapeutic implications from a prospective cohort study. Circulation. 2004;109(8):1004-1009.
4. DeFilippi C, van Kimmenade RR, Pinto YM. Amino-terminal proB-type natriuretic peptide testing in renal disease. Am J Cardiol. 2008;101(3A): 82-88.

5. Varghese K, Cherian G, Abraham UT, Hayat NJ, Johny KV. Predictors of coronary disease in patients with end stage renal disease. Ren Fail. 2001;23(6):797-806.

6. Baigent C, Burbury K, Wheeler D. Premature cardiovascular disease in chronic renal failure. Lancet. 2000;356(9224):147-152.

7. Gardner RS, Chong KS, O’Meara E, Jardine A, Ford I, McDonagh TA. Renal dysfunction, as measured by the modification of diet in renal disease equations, and outcome in patients with advanced heart failure. Eur Heart J. 2007;28(24):3027-3033.

8. Bruch C, Fischer C, Sindermann J, Stypmann J, Breithardt G, Gradaus R. Comparison of the prognostic usefulness of n-terminal pro-brain natriuretic peptide in patients with heart failure with versus without chronic kidney disease. Am J Cardiol. 2008;102(4):469-474.

9. Hartmann F, Packer M, Coats AJ, et al. Prognostic impact of plasma N-terminal pro-brain natriuretic peptide in severe chronic congestive heart failure: a substudy of the Carvedilol Prospective Randomized Cumulative Survival (COPERNICUS) Trial. Circulation. 2004;110(13): 1780-1786.

10. Braunwald E, Antman EM, Beasley JW, et al. ACC/AHA guidelines for the management of patients with unstable angina and non-STsegment elevation myocardial infarction: a report of the American College of Cardiology/American Heart Association Task Force on Practice Guidelines (Committee on the Management of Patients with Unstable Angina). J Am Coll Cardiol. 2000;36(3):970-1062.

11. Ryan TJ, Antman EM, Brooks NH, et al. 1999 Update: ACC/AHA guidelines for the management of patients with acute myocardial infarction: a report of the American College of Cardiology/American Heart Association Task Force on Practice Guidelines (Committee on Management of Acute Myocardial Infarction). J Am Coll Cardiol. 1999;34(3): 890-911.

12. Fox K, Garcia MA, Ardissino D, et al; Task Force on the Management of Stable Angina Pectoris of the European Society of Cardiology; ESC Committee for Practice Guidelines (CPG). Guidelines on the management of stable angina pectoris: executive summary: The Task Force on the Management of Stable Angina Pectoris of the European Society of Cardiology. Eur Heart J. 2006;27(11): 1341-1381.

13. Ma YC, Zuo L, Chen JH, et al. Modified glomerular filtration rate estimating equation for Chinese patients with chronic kidney disease. J Am Soc Nephrol. 2006;17(10):2937-2944.

14. National Kidney Foundation. K/DOQI clinical practice guidelines for chronic kidney disease: evaluation, classification, and stratification. Am J Kidney Dis. 2002;39(2 Suppl 1):S1-S266.

15. Fuster V, Rydén LE, Cannom DS, et al; American College of Cardiology/American Heart Association Task Force on Practice Guidelines; European Society of Cardiology Committee for Practice Guidelines; European Heart Rhythm Association; Heart Rhythm Society. ACC/ AHA/ESC 2006 Guidelines for the Management of Patients with Atrial Fibrillation: a report of the American College of Cardiology/American Heart Association Task Force on Practice Guidelines and the European Society of Cardiology Committee for Practice Guidelines (Writing Committee to Revise the 2001 Guidelines for the Management of Patients With Atrial Fibrillation): developed in collaboration with the European Heart Rhythm Association and the Heart Rhythm Society. Circulation. 2006;114(7):e257-e354.

16. Dickstein K, Cohen-Solal A, Filippatos G, et al; ESC Committee for Practice Guidelines (CPG). ESC Guidelines for the diagnosis and treatment of acute and chronic heart failure 2008. Eur Heart J. 2008;29(19): 2388-2442.

17. Johnson ES, Thorp ML, Yang X, Charansonney OL, Smith DH. Predicting renal replacement therapy and mortality in CKD. Am J Kidney Dis. 2007;50(4):559-565.

18. SPSS Inc. SPSS Missing Values ${ }^{\mathrm{TM}}$ 17.0. Armonk: IBM Corporation; 2007. 
19. Richards M, Nicholls MG, Espiner EA, et al; Christchurch Cardioendocrine Research Group; Australia-New Zealand Heart Failure Group. Comparison of B-type natriuretic peptides for assessment of cardiac function and prognosis in table ischemic heart disease. J Am Coll Cardiol. 2006;47(1):52-60.

20. Goei D, Schouten O, Boersma E, et al. Influence of renal function on the usefulness of $\mathrm{N}$-terminal pro-B-type natriuretic peptide as a prognostic cardiac risk marker in patients undergoing noncardiac vascular surgery. Am J Cardiol. 2008;101(1):122-126.

21. Pfister R, Diedrichs H, Schiedermair A, et al. Prognostic impact of NT-proBNP and renal function in comparison to contemporary multimarker risk scores in heart failure patients. Eur J Heart Fail. 2008;10(3): 315-320.

22. Das SR, Abdullah SM, Leonard D, et al. Association between renal function and circulating levels of natriuretic peptides (from the Dallas Heart Study). Am J Cardiol. 2008;102(10):1394-1398.

23. Herrmann Z, Uhl W, Steinberg HW, Dworschack R. The influence of renal function on NT-proBNP levels in various disease groups. Clin Lab. 2003;49(11-12):649-656.
24. van Kimmenade RR, Januzzi JL Jr, Bakker JA, et al. Renal clearance of B-type natriuretic peptide and amino terminal pro-B-type natriuretic peptide: a mechanistic study in hypertensive subjects. J Am Coll Cardiol. 2009;53(10):884-890.

25. Lee JE, Choi SY, Huh W, et al. N-terminal pro-brain natriuretic peptide levels predict left ventricular systolic function in patients with chronic kidney disease. J Korean Med Sci. 2009;24(Suppl 1):S63-S68.

26. Kragelund C, Grønning B, Køber L, Hildebrandt P, Steffensen R. $\mathrm{N}$-terminal pro-B-type natriuretic peptide and long-term mortality in stable coronary heart disease. N Engl J Med. 2005;352(7):666-675.

27. James SK, Lindahl B, Siegbahn A, et al. N-terminal pro-brain natriuretic peptide and other risk markers for the separate prediction of mortality and subsequent myocardial infarction in patients with unstable coronary artery disease: a Global Utilization of Strategies To Open occluded arteries (GUSTO)-IV substudy. Circulation. 2003;108(3):275-281.
Clinical Interventions in Aging

\section{Publish your work in this journal}

Clinical Interventions in Aging is an international, peer-reviewed journal focusing on evidence-based reports on the value or lack thereof of treatments intended to prevent or delay the onset of maladaptive correlates of aging in human beings. This journal is indexed on PubMed Central, MedLine, the American Chemical Society's 'Chemical Abstracts

\section{Dovepress}

Service' (CAS), Scopus and the Elsevier Bibliographic databases. The manuscript management system is completely online and includes a very quick and fair peer-review system, which is all easy to use. Visit http://www.dovepress.com/testimonials.php to read real quotes from published authors. 